\title{
Torrefaction of residues and by-products from sunflower chain
}

\author{
G. Riva, ${ }^{1}$ E. Foppa Pedretti, ${ }^{1}$ G. Toscano, ${ }^{1}$ D. Duca, ${ }^{1}$ G. Rossini, ${ }^{1}$ C. Mengarelli ${ }^{1}$ \\ ${ }^{1}$ Dipartimento di Scienze Agrarie, Alimentari e Ambientali, Università Politecnica delle Marche, \\ Ancona, Italy
}

\begin{abstract}
The high heterogeneity of some residual biomasses makes rather difficult their energy use and standardisation is a key aspect for these fuel products. Torrefaction is an interesting process used to improve the quality of ligno-cellulosic biomasses and to achieve standardisation. In the present study torrefaction has been employed on residues and by-products deriving from sunflower production chain, in particular sunflower stalks and oil press cake. The thermal behaviour of materials has been studied at first by thermo-gravimetric analysis in order to identify torrefaction temperatures range. Different residence time and torrefaction temperatures have been employed in a bench top torrefaction reactor afterwards. Analyses of raw and torrefied materials have been carried out to assess the influence of the process. As a consequence of torrefaction, the carbon and ash contents increase while the volatilisation range is reduced making the material more stable and standardised. Mass yield, energy yield and energy densification reach values of about $60 \%, 80 \%$ and 1.33 for sunflower stalks and 64 $\%, 85 \%$ and 1.33 for sunflower oil press cake respectively. As highlighted by results, torrefaction is more interesting for sunflower stalks than oil cake and husks because of the different starting characteristics. Untreated oil cake and husks already show a good high heating value and the eventual torrefaction should be mild. On the contrary for sunflower stalks the process is more useful and could be more severe.
\end{abstract}

\section{Introduction}

Solid biomasses have usually different physical and chemical properties making them difficult to use in combustion systems (Virmond et al., 2012; Wu et al., 2011, Jenkins et al.,1998). The main aspects are the presence of moisture, the heterogeneity of the inorganic fraction

Correspondence: Daniele Duca, D3A, Università Politecnica delle Marche, Via Brecce Bianche, 60131 Ancona (AN), Italy.

Tel. +39071220429 , fax +390712204167.

E-mail: d.duca@univpm.it

Key words: stalks, oil press cake, husks, torrefaction.

(c) Copyright G. Riva et al., 2013

Licensee PAGEPress, Italy

Journal of Agricultural Engineering 2013; XLIV(s2):e119

doi:10.4081/jae.2013.s2.e119

This article is distributed under the terms of the Creative Commons Attribution Noncommercial License (by-nc 3.0) which permits any noncommercial use, distribution, and reproduction in any medium, provided the original author(s) and source are credited. and the variability of the organic components, so that many different treatments were studied and developed in ord er to obtain more homogeneous and standardizable biofuel products. In particular there is a great interest in the torrefaction process, for the energy efficiency of the process and the advantages at a qualitative level (Van der Stelt et al., 2011; Uslu et al., 2008). Torrefaction is a thermo-chemical process similar to pyrolysis and carbonization. The process is performed under an inert atmosphere such as nitrogen. During torrefaction the biomass is treated at high temperature to break the chemical bonds of the organic molecules mainly cellulose, hemi-cellulose and lignin. As a consequence, changes of the biomass structure are caused, with the production of volatile and liquid compounds in addiction to a solid torrefied product. This process causes in wood, and generally in lignocellulosic materials, interesting changes for combustion purposes: the increase in energy density, the decrease in hygroscopicity and the ease of grinding (Arias et al., 2008). There are also benefits in terms of biological stabilization and cost reduction during transport and storage, with the possibility to mix the torrefied product with coal for the supply of power plants (Li et al., 2012). In general terms, the behaviour of the torrefied product is similar to that of a traditional solid fossil fuel (Chen and Kuo, 2010).

Torrefaction is a thermal pre-treatment of a solid biomass run without oxygen, at atmospheric pressure and at temperatures between 200 and $300{ }^{\circ} \mathrm{C}$. The first effect on the material is the removal of moisture content and the increase of calorific value. The process determines a loss of solid matter by volatilization up to $30 \%$ by weight, leading inevitably to a loss of energy up to $15 \%$. The lower energy loss is explained by the decrease of oxygen atoms and partly of hydrogen atoms during the process. Energy and mass balances are therefore key factors for the evaluation of the torrefaction process (Chen et al., 2011). The loss of hydroxyl groups, particularly in wood, but in general in all ligno-cellulosic matrices, is also responsible for the lower hygroscopy of torrefied materials if compared with untreated materials.

The present work was carried out within the "Extravalore" project, funded by MIPAAF (the Italian Ministry of Agricultural, Food and Forestry Policies), about the valorisation of by-products deriving from the biodiesel production process. The present paper aims in particular to find a possible valorisation of sunflower chain residues. The torrefaction of sunflower stalks and oil press cake has therefore been studied in order to evaluate the characteristics and behaviour of the torrefied biomass and to assess the advantages that could be obtained with these different starting materials.

\section{Material and methods}

\section{Introduction}

Materials were obtained within the Extravalore project from seeds and residues of sunflowers cultivated in 0simo (Marche region) and then processed in the Biomass Lab of D3A department of Università Politecnica delle Marche. 


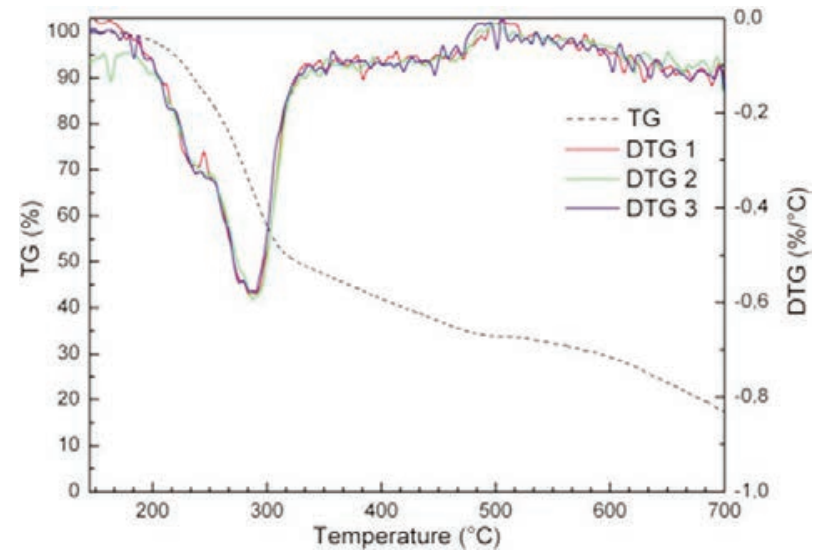

Figure 1. Curves produced from the thermo-gravimetric analysis of sunflower stalks. Overlapping of three repetitions..

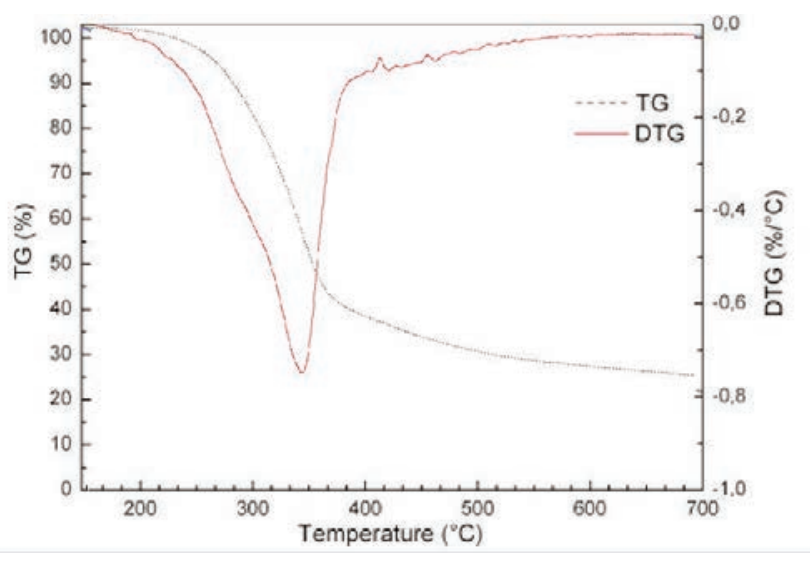

Figure 3. Curves produced from the thermo-gravimetric analysis of sunflower husks

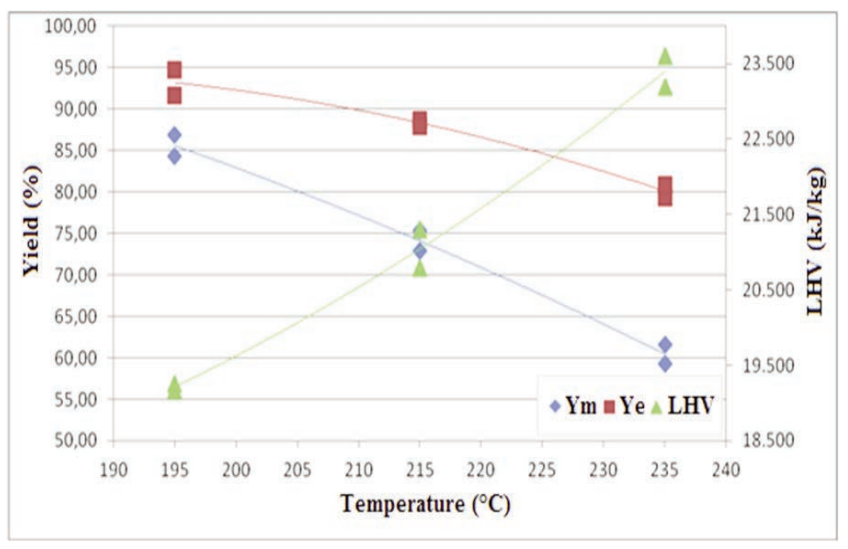

Figure 5. Performance of process yields as a function of temperature (mass yields, "Ym", and energy yields, "Ye") and lower heating value (LHV) in samples of torrefied sunflower stalks at 60 minutes

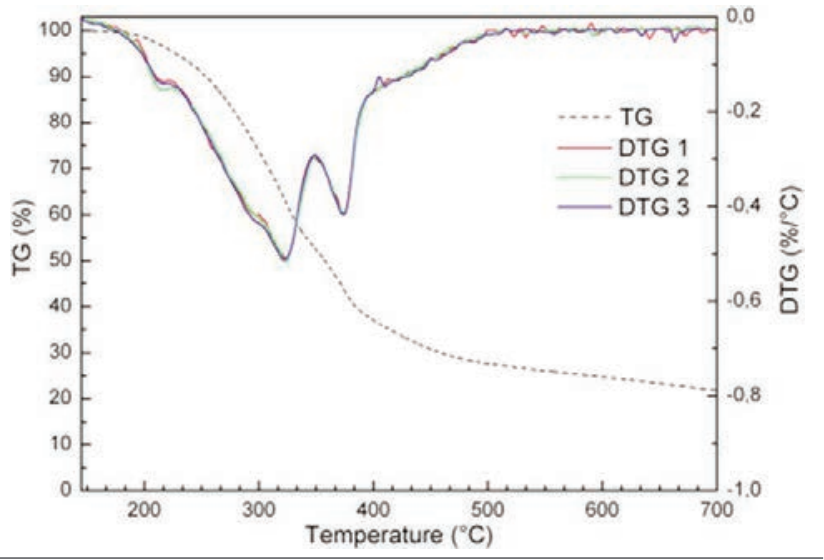

Figure 2. Curves produced from the thermo-gravimetric analysis of sunflower cake. Overlapping of results of three repetitions

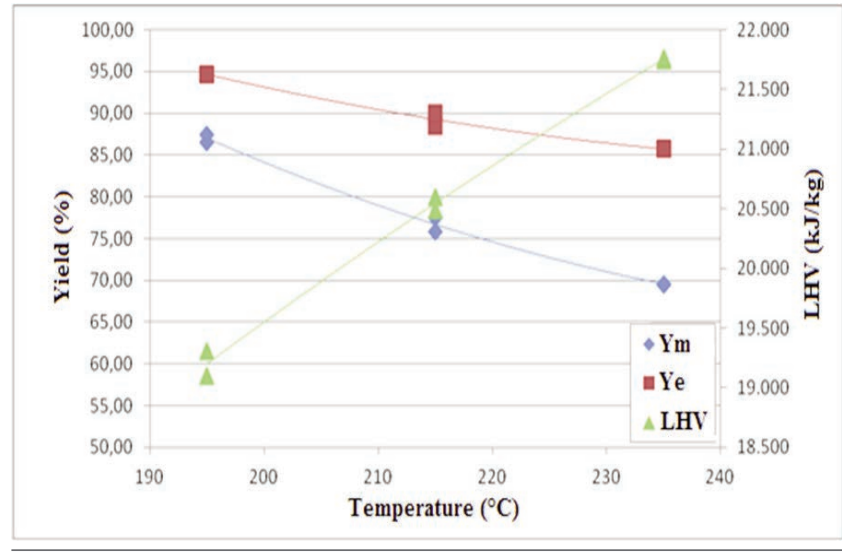

Figure 4. Performance of process yields as a function of temperature (mass yields, "Ym", and energy yields, "Ye") and lower heating value (LHV) in samples of torrefied sunflower stalks at 30 minutes.

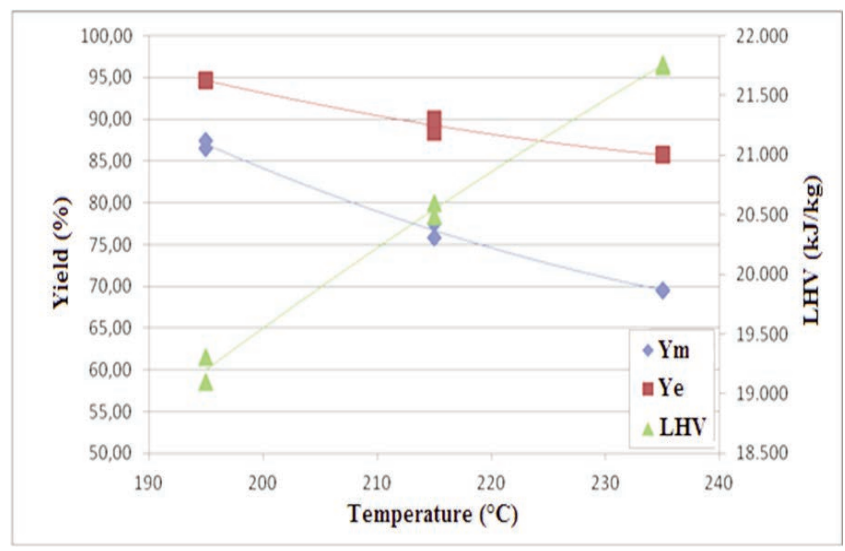

Figure 6. Performance of process yields as a function of temperature (mass yields, "Ym", and energy yields, "Ye") and lower heating value (LHV) in samples of torrefied sunflower cake at 30 minutes 


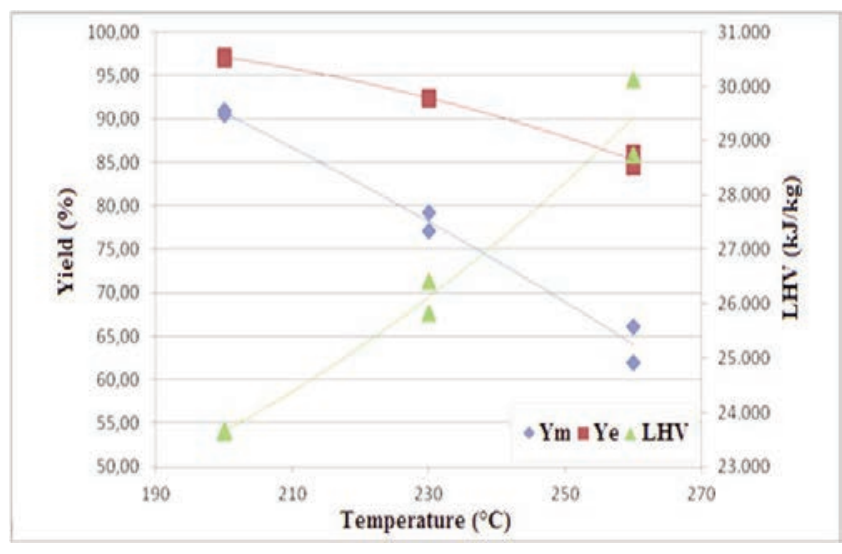

Figure 7. Performance of process yields as a function of temperature (mass yields, "Ym", and energy yields, "Ye") and lower heating value (LHV) in samples of torrefied sunflower cake at 60 minutes

The experimental work has been performed as follows:

- sample preparation;

- thermo-gravimetric analysis to define the torrefaction temperatures (Tts) for the later tests in the reactor;

- torrefaction tests;

- characterisation of raw and torrefied materials by thermo-gravimetric, proximate and ultimate analyses;

Table 1. Operative setting parameters used for the tested materials.

\begin{tabular}{crrr}
$\begin{array}{c}\text { sunflower stalks } \\
\text { Temp. } \\
\left({ }^{\circ} \mathbf{C}\right)\end{array}$ & $\begin{array}{r}\text { Time } \\
(\text { min) }\end{array}$ & $\begin{array}{r}\text { sunflower cake } \\
\text { Temp. } \\
\left({ }^{\circ} \mathbf{C}\right)\end{array}$ & $\begin{array}{r}\text { Time } \\
(\text { min })\end{array}$ \\
\hline 195 & 30 & 200 & 30 \\
& 60 & 230 & 60 \\
\hline 215 & 30 & & 60 \\
& 60 & 260 & 91 \\
235 & 30 & & 60 \\
\hline
\end{tabular}

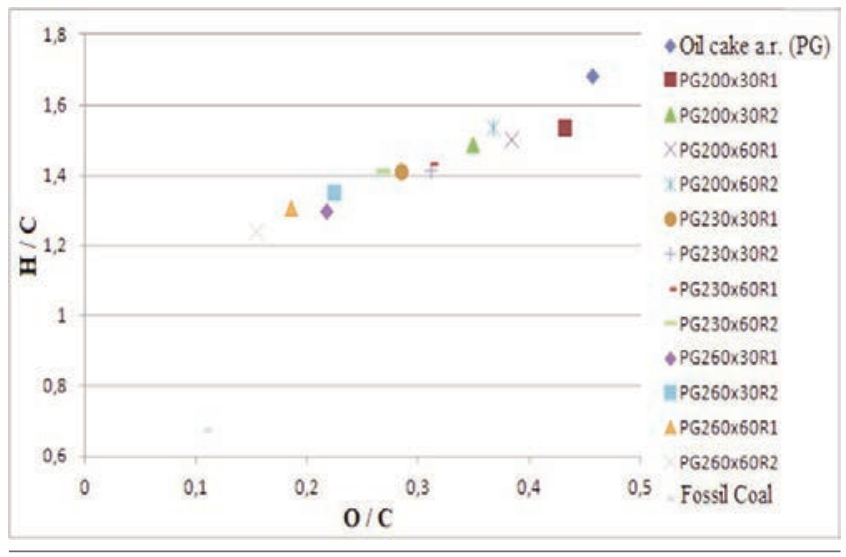

Figure 9. Van Krevelen diagram obtained from the elemental characterisation of row and torrefied sunflower cake at different conditions. Coal is reported for comparison. (Source for the coal data: Phyllis/ECN, 1998)

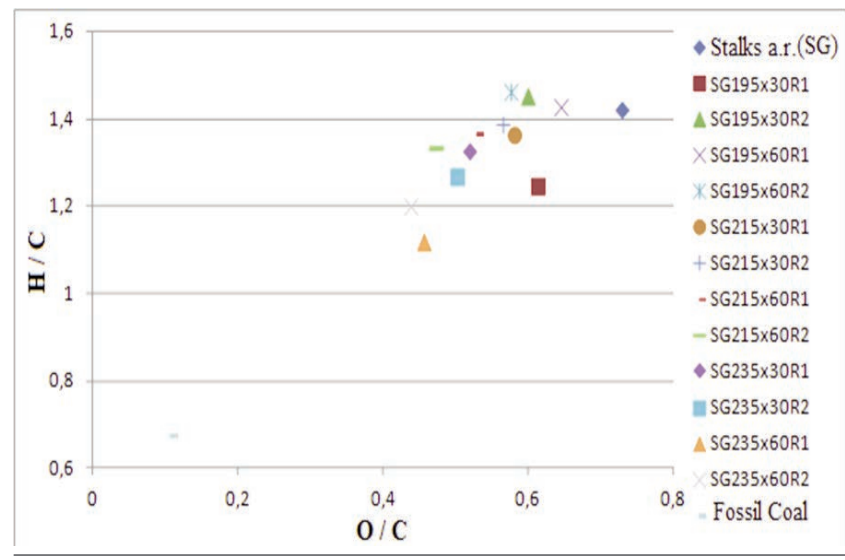

Figure 8. Van Krevelen diagram obtained from the elemental characterisation of row and torrefied sunflower stalks at different conditions. Coal is reported for comparison. (Source for the coal data: Phyllis/ECN, 1998)

The steps are described in details.

\section{Sample preparation}

The materials employed in the present study and the related moisture contents at sampling are the following:

- sunflower stalks: $18,0 \%$

- sunflower press cake: $9,7 \%$

- sunflower husks: $6,7 \%$

These materials were dried at $105^{\circ} \mathrm{C}$ overnight in a forced ventilation oven (MPM INSTRUMENTS), then grinded in a cutting mill (RETSCH). All materials, the raw and processed ones, were stored in air-tight plastic containers at room temperature until analyses were carried out.

\section{Thermogravimetric analysis}

The thermal behaviour of raw and torrefied biomass was studied by means of thermo-gravimetric analysis, carried out with a thermogravimetric analyser (LINSEIS). The function of weight loss recorded for the whole test, with increasing temperature and time, is called thermo-gravimetric curve (TG). The TG was then processed to obtain the first derivative thermo-gravimetric curve (DTG). For all experimental runs, $20 \mathrm{mg}$ of material were heated from ambient temperature up to $700{ }^{\circ} \mathrm{C}$. The first analysis was made at $5{ }^{\circ} \mathrm{C} \mathrm{min}-1$ heating rate to define the temperatures for the consecutive torrefaction tests to be performed in the reactor. This rate has been used to allow a more homogeneous sample heating, as reported by some authors (Grønli et al., 2002), and to simulate the heating rate of the reactor. By means of DTG results the Tts for the tests in the torrefaction reactor have been defined. At a later stage, TGs of torrefied and raw materials were carried out to observe the influence of torrefaction conditions on material structure. A faster heating rate $\left(20^{\circ} \mathrm{C} \mathrm{min}^{-1}\right)$ was employed in order to reduce analytical time. Nitrogen was used during the analysis at a flow rate of $100 \mathrm{~cm} 3 \mathrm{~min}^{-1}$ to maintain an inert environment. To evaluate the experimental reproducibility each sample has been analysed for three times and the DTGs obtained were almost superimposable.

\section{Torrefaction tests}

Torrefaction was carried out in a heated bench-top reactor (PARR). The sample (10 g) was inserted in a sample holder and placed in the 
Table 2: European standards and instruments employed for heating value, proximate and ultimate analyses

\begin{tabular}{lll}
\hline Operation/Analysis & Method & Instrument \\
Sample preparation & UNI EN 14780 & Grinder mill \\
Moisture content & UNI EN 14774 & Stove at T $=105^{\circ} \mathrm{C}-$ Thermo-gravimetric scale \\
\hline Ash content & UNI EN 14775 & Muffle at T $=550^{\circ} \mathrm{C}-$ Thermo-gravimetric scale \\
C,H,N,O & UNI EN 15104 & Elemental analyser \\
\hline High heating value & UNI EN 14918 & Calorimeter \\
Lower heating value & UNI EN 14918 & Calorimeter- Elemental analyser \\
\hline Thermo-gravimetric profile & Internal method & Thermo-gravimetric analyser \\
\hline
\end{tabular}

Table 3: Sunflower stalks - Analysis of torrefied products (each result is an average of two repetitions)

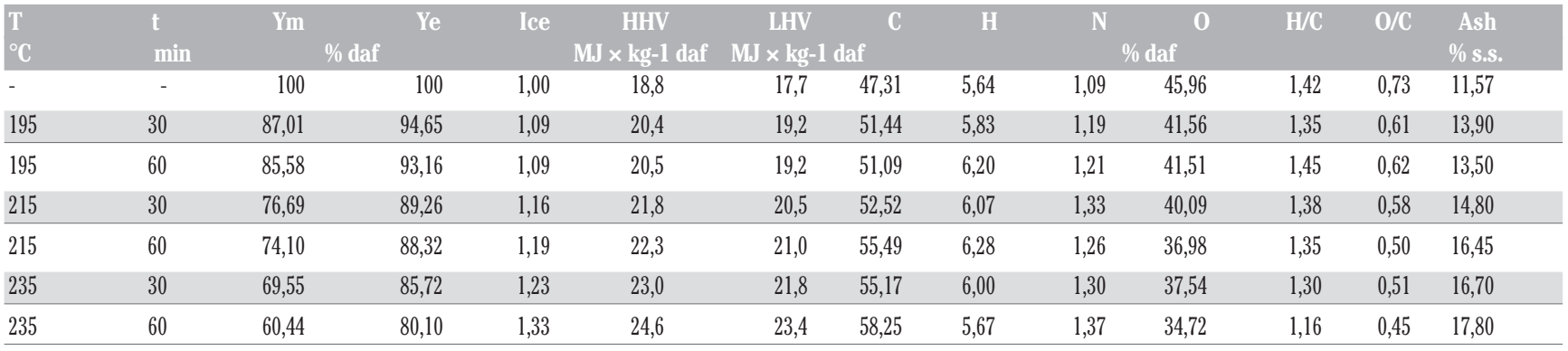

Table 4: Sunflower cake - Analysis of torrefied products (each result is an average of two repetitions)

\begin{tabular}{|c|c|c|c|c|c|c|c|c|c|c|c|c|c|}
\hline $\mathrm{T}$ & $\mathrm{t}$ & Ym & Ye & Ice & HHV & LHV & C & $\mathrm{H}$ & $\mathbf{N}$ & 0 & $\mathrm{H} / \mathrm{C}$ & $0 / C$ & Ash \\
\hline${ }^{\circ} \mathrm{C}$ & $\min$ & & & & $\mathrm{kg}-1$ & MJ $\times$ kg & & & & & & & $\%$ s.s. \\
\hline - & - & 100 & 100 & 1,00 & 23,7 & 22,1 & 55,17 & 7,80 & 3,47 & 33,56 & 1,68 & 0,46 & 4,71 \\
\hline 200 & 30 & 91,70 & 98,87 & 1,08 & 25,3 & 23,8 & 58,19 & 7,39 & 4,29 & 30,15 & 1,52 & 0,39 & 5,15 \\
\hline 200 & 60 & 90,69 & 97,08 & 1,07 & 25,2 & 23,7 & 59,16 & 7,55 & 3,70 & 29,59 & 1,52 & 0,38 & 5,20 \\
\hline 230 & 30 & 81,09 & 92,20 & 1,14 & 26,7 & 25,1 & 63,92 & 7,58 & 4,55 & 23,96 & 1,41 & 0,28 & 5,90 \\
\hline 230 & 60 & 78,18 & 92,41 & 1,18 & 27,7 & 26,1 & 63,74 & 7,62 & 4,08 & 24,57 & 1,42 & 0,29 & 5,80 \\
\hline 260 & 30 & 71,97 & 89,88 & 1,25 & 29,1 & 27,6 & 67,69 & 7,53 & 4,89 & 19,90 & 1,33 & 0,22 & 6,40 \\
\hline 260 & 60 & 64,08 & 85,27 & 1,33 & 31,0 & 29,4 & 71,48 & 7,64 & 4,75 & 16,14 & 1,28 & 0,17 & 7,30 \\
\hline
\end{tabular}

Table 5: Energy characterisation of sunflower husks

\begin{tabular}{|c|c|c|c|c|c|c|c|c|}
\hline \multirow{2}{*}{\multicolumn{3}{|c|}{$\begin{array}{c}\text { HHV LHV } \\
\text { MJ } \times \text { kg } \\
\text { MJ } \times \text { kg }\end{array}$}} & H & $\mathbf{N}$ & 0 & $\mathrm{H} / \mathrm{C}$ & $0 / C$ & Ash \\
\hline & & & & & & & & \\
\hline $\begin{array}{c}-1 \text { daf } \\
23,2\end{array}$ & $\begin{array}{r}-1 \text { daf } \\
21,6\end{array}$ & 56,60 & 7,55 & 1,65 & $\begin{array}{l}\text { daf } \\
34,19\end{array}$ & 1,59 & 0,45 & $\begin{array}{c}\% \text { s.s. } \\
3,90\end{array}$ \\
\hline
\end{tabular}

centre of the reactor in order to avoid the direct contact between the biomass and the hot reactor walls. Each test was performed with flowing nitrogen gas to maintain an inert environment inside the reactor. Temperature was controlled during the test using a PID controller. The temperature program consists of a slow heating rate $\left(5^{\circ} \mathrm{C} \mathrm{m} \mathrm{in}^{-1}\right)$ from ambient temperature up to $\mathrm{Tt}$, followed by an isothermal step defined as residence time (Rt). The sample was then cooled to room temperature by a water cooling system under continuous flow of nitrogen through the reactor. The solid sample was then weighted and collected for further analyses. Different Tts and Rts have been evaluated for torrefaction tests. Each test was performed in triplicate. Tts for the torrefaction tests were chosen from DTG at $5{ }^{\circ} \mathrm{C}$ min $^{-1}$ within the reactivity range of hemicelluloses, defined as the range between the initial degradation temperature $\left(\mathrm{T}_{\text {onset }}\right)$ and the maximum degradation rate temperature $\left(\mathrm{T}_{\text {shoulder }}\right)$. This range has been equally divided into three parts, and the selected Tts are reported in table 1. Sunflower husks were not tested for torrefaction because their energy characterisation gave interesting results and the pre-treatment would not be so useful.

\section{Heating value, proximate and ultimate analyses of materials}

To evaluate the influence of the torrefaction conditions on biomass quality, raw and torrefied biomass have been analysed. Heating value, proximate and ultimate analyses were performed for all materials in accordance with the European standards, as summarized in table 2.

Process parameters were calculated to evaluate how temperature and time of the torrefaction treatment influence biomass quality and composition according to the following equations:

$$
\begin{array}{ll}
\mathrm{M}_{\mathrm{Y}}(\%)=\left(\mathrm{m}_{\text {tor }} \mathrm{m}_{\text {bio }}\right) \bullet 100 \\
\mathrm{I}_{\text {ed }}=\mathrm{LHV}_{\text {tor }} / \mathrm{LHV}_{\text {bio }} \\
\mathrm{E}_{\mathrm{Y}}(\%)=\mathrm{M}_{\mathrm{Y}} \bullet \mathrm{I}_{\mathrm{ed}}
\end{array}
$$

where $M_{Y}$ and $E_{Y}$ are mass and energy yields and represent the amount of matter and energy remained after the process; $I_{\text {ed }}$ is the energy densification index which represents the increasing of the energy contained in the material; $m$ is the mass of the material, and LHV is the lower heating value. Subscripts tor and bio are referring to torrefied and raw biomass respectively. All quantities are expressed on dry ash-free base (daf).

Taking into account the results of elemental analysis, $\mathrm{H} / \mathrm{C}$ and $0 / \mathrm{C}$ atomic ratios have been calculated and plotted in a Van Krevelen diagram. 


\section{Results and discussion}

\section{Thermogravimetric analysis}

The results of thermo-gravimetric analyses carried out on the starting materials are reported below.

The sunflower stalks produce DTG curves showing a clear overlap of the peak of hemicelluloses with that of cellulose (Figure 1). Unlike classical ligno-cellulosic biomasses the kinetics of thermal degradation is rather low, especially regarding cellulo ses.

It can be noted also a certain diversity of response among the 3 repetitions and this is related, most likely, to the heterogeneity of the material. The stalk, in fact, consists of two main components, a cortex and a marrow, with different specific weights that are difficult to mix after grinding, and consequently make difficult also the test sample homogenization.

The $\mathrm{T}_{\text {onset }}$ of this material is about $180-190^{\circ} \mathrm{C}$ and the $\mathrm{T}_{\text {shoulder }}$ about $240-250^{\circ} \mathrm{C}$. For sunflower stalks were selected a Tmin and Tmax close, respectively, to the point of "onset" and "shoulder" (Tmin $=195{ }^{\circ} \mathrm{C}$, $\left.\operatorname{Tmax}=235^{\circ} \mathrm{C}\right)$, and a Tint in the center $\left(215^{\circ} \mathrm{C}\right)$.

The sunflower cake cannot be considered a classic ligno-cellulosic biomass as surely also consists of fat. Residual oil deriving from the mechanical pressing of seeds in fact still remains inevitably trapped within the matrix of the cake in a variable percentage.

Looking at the thermal profile obtained from the TGA analysis (Figure 2) at least one peak more is observed. The peak corresponding to the volatilization of the oil produces its maximum at a temperature of $375^{\circ} \mathrm{C}$.

On the whole, the kinetics of degradation does not reach high values. The first peak that is encountered, p robably associated with the decomposition of the hemi-cellulose fraction, appears to be lower and moved to the left.

For this product were chosen 3 temperatures included in the range of holo-celluloses degradation: $200^{\circ} \mathrm{C}, 230^{\circ} \mathrm{C}$ and $260^{\circ} \mathrm{C}$.

The thermal profile obtained from the TGA analysis of sunflower husks (Figure 3) shows a clear overlap of the peak of hemi-celluloses with that of cellulose. The highest cellulose degradation rate is reached at about $340^{\circ} \mathrm{C}$, a rather high temperature with respect to the other materials tested. However the degradation kinetics are higher. This behaviour is typical of woody material.

\section{Results of torrefaction tests and characterisation of raw and torrefied materials}

The results of chemical and energetic analyses for raw and torrefied samples are listed as follows.

Results of the characterisation of torrefied sunflower stalks are reported in Table 3 together with the process yields.

While the calorific value and the energy concentration index show an increase, the mass yield and energy yield confirm the usual downward trend, reaching values of respectively $60 \%$ and $80 \%$ with the most critical conditions.

The main results obtained by the treatment of sunflower stalks to different operating conditions are shown in graphic form (Figures 4 and 5).

Table 4 shows the results obtained from the analysis of torrefied sunflower cake: similarly to what observed for the other biomasses, also in this case a torrefaction more extreme in terms of temperature and/or time leads to an increase in carbon content and heating value and, in parallel, a reduction in mass yield and energy yield.

Figures 6 and 7 show in graphic form the values of mass yield, energy yield and lower heating value in function of torrefaction temperature and applying an isotherm of 30 and 60 minutes respectively.
The results of chemical and energetic analyses carried out on sunflower husks are reported in Table 5.

Untreated sunflower husk is an interesting material for energy application due to its high energy content, limited nitrogen and ash content. The most important limit is the poor bulk density but this cannot be solved by torrefaction.

\section{Van Krevelen diagram about sunflower stalks and cake}

The torrefaction treatment determines changes in the organic structure of all biomasses. In all cases an increase in the concentration of carbon (C) associated with a decrease of the oxygen content $(0)$ has been observed. On the other hand the concentration of hydrogen $(\mathrm{H})$ oscillates without showing a definable trend.

Generally, the structure of torrefied products tends to assume a composition that more and more resembles to that of conventional solid fuels (e.g. hydrocarbon structure of the coal) when increasing the severity of the process itself.

Plotting the indices $0 / \mathrm{C}$ (on $\mathrm{x}$-axis) and $\mathrm{H} / \mathrm{C}$ (on y-axis) of each torrefied product, expressed as atomic ratio, we obtain the so-called "Van Krevelen diagrams." These diagrams highlight the structural changes and allow us to better interpret the effect of torrefaction treatment on the quality of biomasses to be used in combustion.

Figures 8 and 9 show the Van Krevelen diagrams of each material.

In general, it can be seen that the experimental points are arranged along an imaginary line that originates from the characteristic values of the starting biomasses (upper right in the respective graphs) and extends to gradually lower values of $\mathrm{H} / \mathrm{C}$ and $0 / \mathrm{C}$ (toward the origin of the axes). The more extreme is the torrefaction ( $>$ temperatures and/or $>$ time), the more enriched in carbon than oxygen and hydrogen are the torrefied products. As a consequence their organic struct ure moves away from that of the original biomass and tends progressively to take on characteristics similar to that of coal, traditional solid fuel, acquiring at the same time also hydrophobic properties typical of nonpolar hydrocarbons.

\section{Conclusions}

The thermo-gravimetric analyses put in evidence the heterogeneity of the organic fraction which is basically ligno-cellulosic for sunflower stalks while it is much more complex in the cake for the presence of different matrices (oil). Even the inorganic component is present in varying amounts in the different residual biomasses, with values ranging from $3.9 \%$ for sunflower husks to $11.6 \%$ f or stalks. These values are significantly higher than what is found in woody biomasses. The energy concentration, however, proves to be quite interesting, in particular for the sunflower cake and husks.

The torrefaction treatment provides interesting qualitative improvements of all the biomass treated. However, the "price" that is paid in this process is the inevitable loss of mass, and therefore of en ergy, of the treated material. This depends on the dismissal of organic compounds that are formed by the thermal degradation of macromolecules (hemicelluloses, cellulose and lignin) and that volatilise with different kinetics characteristics of each biomass (as evident in their thermo-gravimetric profiles).

The torrefaction treatment reaches a balance when the quality standard of products finds a comp romise with the maximum performance of the treatment in terms of mass and energy. This should be functional to the energy use that it is intended, and therefore to the needs of the energy conversion system powered. The empirical study of the tor- 
refaction process is a critical step that should be properly programmed according to the energy performances desired from the torrefied products and in order to identify the best conditions of the treatment. This approach become mandatory due to the structural and chemical variability of biomasses, even within the same product category. Materials with high moisture content and a molecular structure particularly rich in oxygen (and then with higher $0 / \mathrm{C}$ ), such as sunflower stalks, when subjected to heat treatment, undergo more changes in mass but, at the same time, acquire significant benefits in terms of energy concentration.

In this perspective, from a technical point of view, it is better to employ torrefaction with materials such as sunflower stalks, while for sunflower cake and husks a better alternative or a direct energy application should be found. However, from a practical point of view, the torrefaction process is more feasible with residues produced in processing steps than in cultivation, due to logistic aspects.

\section{References}

1. Virmond E, De Sena RF, Albrecht W et al. Characterisation of agroindustrial solid residues as biofuels and potential application in thermochemical processes. Waste Manage 2012;32(10):1952-61.

2. Wu MR, Schott DL, Lodewijks G. Physical properties of solid bio- mass. Biomass Bioenerg 2011;35(5):2093-105.

3. Jenkins BM, Baxter LL, Miles Jr TR et al. Combustion properties of biomass. Fuel Process Technol 1998;54(1-3):17-46.

4. Van der Stelt MJC, Gerhauser H, Kiel JHA et al. Biomass upgrading by torrefaction for the production of biofuels: A review. Biomass Bioenerg 2011;35(9):3748-62.

5. Uslu A., Faaij APC, Bergman PCA. Pre-treatment technologies, and their effect on international bioenergy supply chain logistics. Techno-economic evaluation of torrefaction, fast pyrolysis and pelletisation. Energy 2008;33(8):1206-23.

6. Arias B, Pevida C, Fermoso J et al. Influence of torrefaction on the grindability and reactivity of woody biomass. Fuel Process Technol 2008;89(2):169-75.

7. Li J, Brzdekiewicz A, Yang W et al. Co-firing based on biomass torrefaction in a pulverized coal boiler with aim of $100 \%$ fuel switching. Appl Energ 2012;99(0):344-54.

8. Chen WH, Kuo PC. A study on torrefaction of various biomass materials and its impact on lignocellulosic structure simulated by a thermogravimetry. Energy 2010;35(6):2580-86.

9. Chen WH, Cheng WY, Lu KM et al. An evaluation on improvement of pulverized biomass property for solid fuel through torrefaction. Appl Energ 2011;88(11):3636-44.

10. Grønli MG, Várhegyi G, Di Blasi C. Thermogravimetric Analysis and Devolatilization Kinetics of Wood. Ind Eng Chem Res 2002;41(17):4201-08. 